\title{
2021 Everett Mendelsohn Prize
}

\author{
Karen Rader ${ }^{1} \cdot$ Marsha Richmond $^{2}$
}

Accepted: 1 February 2021 / Published online: 15 February 2021

(c) The Author(s), under exclusive licence to Springer Nature B.V. part of Springer Nature 2021

It is our pleasure to announce the recipient of the 2021 Everett Mendelsohn Prize, awarded annually to the author of the article published in the journal during the previous three years that best exemplifies the virtues of originality, contribution to scholarship, and significance for the history of biology. In judging the 2021 award, the prize committee (consisting of the Co-Editors in Chief and the Associate Editors, Luis Campos and Nick Hopwood) considered all 65 articles appearing in volumes 51 (2018), 52 (2019), and 53 (2020).

The winner for 2021 is Jean-Baptiste Grodwohl, whose essay, "Animal Behavior, Population Biology and the Modern Synthesis (1955-1985)," appeared in the special issue on the Modern Synthesis in volume 52, issue 4 (2019), pp. 597-633. Although modestly aiming to treat "the history of animal behavior studies after the synthesis period," Grodwohl's article addresses broad issues reflecting a process of repositioning the Modern Synthesis within evolutionary biology from 1960 to 1980. By focusing on three important adoptions - of natural selection by students of animal behavior, mathematics (especially modeling) by naturalists, and molecular tools by population biologists-Grodwohl tells an expansive story of how fields previously lacking a theoretical framework not only advanced the understanding of animal behavior but, in so doing, transformed the Modern Synthesis as well. In contrast to the verbal disputes carried on by the founders of the synthesis in the 1940s and 1950s, Grodwohl argues that the new "integrative agendas and interdisciplinary relationships in evolutionary biology" led to the "adaptationist program" of recent decades.

Along the way, the tale that unfolds is rich in its overall narrative and offers intriguing insights into the twists and turns of cross- and interdisciplinary biological work. Grodwohl relates, for example, how conversations between psychologist Anne Roe and her vertebrate paleontologist husband George Gaylord Simpson led to their concerted efforts to integrate behavior into the synthesis. In the mid-1950s, they brought together interdisciplinary groups of scientists at two symposia, which

\footnotetext{
Karen Rader

journalofthehistoryofbiology@gmail.com

1 Virginia Commonwealth University, Richmond, VA, USA

2 Wayne State University, Detroit, MI, USA
} 
first initiated discussions about how field studies could become part of theoretical biology. Yet such integrative studies in ethology, behavioral ecology, and sociobiology were hindered by their disparate institutional homes, distinct territorial boundaries, and divergent interpretations and understanding of behavior. Researchers surmounted these impediments by embracing questions and tools from population genetics and population ecology, and they advanced studies in sociobiology and behavioral ecology by developing modeling methods and computer simulations. Yet the subsequent adoption of molecular tools-incorporating molecular data into systematics and studying natural selection at the molecular level-not only promoted the population biology of behaviors, but also, synergistically, molecular biology itself. Supported by extensive archival research, oral history interviews, and a wealth of additional primary and secondary sources, Grodwohl concludes that, despite significant differences, such integrative approaches, rather than disrupting or displacing the classical Modern Synthesis, shared interests with the founders. By the 1980s, he proposes, students of animal behavior had become "spokesmen of the Modern Synthesis" who were "aligned within the same "neo-Darwinian orthodoxy"" (629). The case of animal behavior, in short, reveals that, far from being incorporated into a synthesis, disciplines could pursue more complex processes of engagement and transformation that, in turn, shaped evolutionary biology.

Jean-Baptiste Grodwohl, a historian of science trained in Paris, has worked in Brazil, the United Kingdom, and Japan. He is now teaching in the Department of History and Philosophy of Science at the University of Paris. His current work concerns the history of population genetics after 1945 and, more specifically, tackles how mathematical models and empirical research programs in this field were affected by the introduction of molecular methods. On behalf of the 2021 Prize Committee and Springer-Nature International Publishing, we congratulate Dr. Grodwohl on winning the 2021 Mendelsohn Prize. His article will be freely available on the Journal of the History of Biology website in March and April 2021, and he will receive an honorarium of $\$ 500$.

Over the past three years, $J H B$ has published many other outstanding articles. We wish to recognize three additional essays as highly commended, listed in alphabetical order.

Clare Button's article, "James Cossar Ewart and the Origins of the Animal Breeding Research Department in Edinburgh, 1895-1920," JHB 51, 4 (2018): 445-477, provides the prehistory of the 1919 founding of the Animal Breeding Research Department in Edinburgh, which in 1930 became the Institute of Animal Genetics. Button carefully traces the making of an internationally important genetics research institute to the previously little-studied zoologist James Cossar Ewart, who in 1895 envisioned the importance of encouraging scientific breeding practices-five years before the rediscovery of Gregor Mendel's work-and worked tirelessly to gain the necessary funding. Clare Button is Archivist at Barts and The London School of Medicine and Dentistry at Queen Mary University of London.

Alexandra Rizhinashvili, in "Production Hydrobiology in the USSR under the Pressure of Lysenkoism: Vladimir I. Zhadin's Forgotten Theory of Biological Productivity (1940)," JHB 53, 1 (2020): 105-139, provides a highly informative view of how Lysenko's dogmas influenced sciences other than genetics. Tracing 
the development of the hydrobiologist Vladimir Zhadin's theory of biotic production within river systems recently disturbed by reservoir construction, Rizhinashvili teases out the intricate interplay between political ideology and scientific views of adaptation and adds a sophisticated account of a case that advances the understanding of how Lysenkoism influenced scientific disciplines in Russia and its satellites. Alexandra Rizhinashvili is Head of Department and Senior Researcher in the Department of the History of Evolutionary Theory and Ecology, S. I. Vavilov Institute for the History of Science and Technology of the Russian Academy of Sciences, St. Petersburg Branch.

In "The 'Disadapted' Animal: Niko Tinbergen on Human Nature and the Human Predicament," JHB 51, 2 (2018): 191-221, Marga Vicedo reconstructs why and how the ethologist Tinbergen transitioned from studies of the social behavior of animals, for which he shared the 1973 Nobel Prize in Physiology or Medicine, to studying human behavior. Analyzing Tinbergen's personal life and career alongside topics discussed in his academic presentations and publications (and those of close colleagues), Vicedo offers a convincing interpretation of Tinbergen's concern-grounded in the social turmoil of the 1960s and 1970s-that evolutionarily determined dysfunctional elements in behavior might jeopardize the survival of the human species. Marga Vicedo is professor and director of undergraduate studies in the Institute for the History and Philosophy of Science and Technology at the University of Toronto.

These articles will be made freely available on the Journal of the History of Biology website in March and April 2021. 